\title{
Barriers to employing persons with mental retardation "Learnable" from the perspectives of Special education students at Al-Quds Open University -Nablus Branch
}

\author{
Fakhry Mustafa Dwekat
}

Faculty of Educational Sciences Open University -Nablus Branch

\begin{abstract}
The current study aimed at investigating the barriers to employing persons with mental disabilities "Learnable" from the perspectives of the students of special education at Al-Quds Open University in Nablus Branch in addition to examining the role o of gender, educational level and residence on the students' perspectives. The sample of the study consisted of 68 male and female students. To achieve the study objectives, the researcher constructed a questionnaire which was administered on the sample after being validated .Results revealed that the order of barriers to employing persons with mental disabilities was the following: Family barriers $(68.67$ \%), barriers related to Vocational Rehabilitation Programs( $65.20 \%)$, media barriers (63.07 \%), barriers related to the community and environment $(55.47 \%)$ whereas the total degree of the barriers scored $(63.10 \%)$. Furthermore, the results indicated that there were no statistically significant differences between the students' perspectives due to the variables of gender, educational level and residence. The results were analyzed and discussed according to the literature review so as to offer some valuable recommendations. The current study aimed at investigating the barriers to employing persons with mental disabilities "Learnable" from the perspectives of the students of special education at Al-Quds Open University in Nablus Branch in addition to examining the role o of gender, educational level and residence on the students' perspectives. The sample of the study consisted of 68 male and female students. To achieve the study objectives, the researcher constructed a questionnaire which was administered on the sample after being validated .Results revealed that the order of barriers to employing persons with mental disabilities was the following: Family barriers $(68.67 \%)$, barriers related to Vocational Rehabilitation Programs $(65.20 \%)$, media barriers (63.07 \%), barriers related to the community and environment $(55.47 \%)$ whereas the total degree of the barriers scored( 63.10 $\%)$. Furthermore, the results indicated that there were no statistically significant differences between the students' perspectives due to the variables of gender, educational level and residence. The results were analysed and discussed according to the literature review so as to offer some valuable recommendations.
\end{abstract}

Keywords: Barriers; persons with mental disabilities, "Learnable " students of special education

Citation: Dwekat, prepare a program in the Islamic culture based on self-regulated learning for Developing some religious concepts and tourism attitudes of Faculty of Tourism and Hotels Students. SVU-Journal of abstract 2019, Vol.1: pp7(retrieved from the Journal of Educational Sciences; 2018, No.34; pp161).

Copyright: Publisher South Valley University. This is an open access article distributed under the terms of the creative common attribution license, which permits unrestricted use, distribution and reproduction in any medium provided the original author and source are created. 